\title{
Genetic variability of traits recorded during 100-day stationary performance test and inbreeding level in Polish warmblood stallions
}

\author{
Alicja Borowska', Anna Wolc ${ }^{1,2}$ and Tomasz Szwaczkowski ${ }^{1}$ \\ 'Department of Genetics and Animal Breeding, Poznan University of Life Sciences, Poznań, Poland, ${ }^{2}$ Department of \\ Animal Science, lowa State University, Ames, USA
}

\begin{abstract}
The objectives of this study were to estimate direct heritability of 30 conformation and performance traits evaluated during 100-day stationary performance test and to predict the genetic effects in Polish Warmblood stallions. Inbreeding coefficients were estimated as well. Moreover, phenotypic and genetic trends were derived. The data were extracted from the database of the Polish Horse Breeding Association. The analysis included 494 warmblood stallions, which performed during 100-day test in the years 2002-2008 at two Polish Training Centres. Pedigree data comprised 8512 individuals. Restricted maximum likelihood was employed to estimate parameters under an additive genetic model (including fixed effects: age of stallion, breed, year and place of performance test). Nonzero inbreeding coefficients were estimated for 88 stallions with performance records as well as for 458 unrecorded ancestors. Average inbreeding level for the stallions with records was $0.29 \%$, whereas for all inbred individuals $-1.69 \%$. The average completeness of the pedigrees, expressed as Cassell coefficient, for the recorded stallions was $42.47 \%$. The heritability estimates varied from 0.14 (character) to 0.87 (total index). Relatively high heritabilities were found for jumping-ability traits. In general, the genetic trends for studied traits were negligibly positive.
\end{abstract}

Keywords: warmblood stallions, performance tests, heritability, inbreeding

\section{Zusammenfassung}

\section{Genetische Variabilität von Merkmalen ermittelt durch stationäre Leistungsprüfung über $\mathbf{1 0 0}$ Tage und Inzuchtniveau polnischer Warmbluthengste}

Die Zielsetzung der Studie war die Schätzung der direkten Erblichkeit von 30 Zucht- und Leistungsmerkmalen, die durch eine 100-Tage-Stationäre-Leistungsprüfung bewertet wurden. Ein weiteres Ziel der Arbeit bestand in der Prognose der genetischen Effekte bei Warmblut-Hengsten. Die Inzuchteffekte wurden berücksichtigt. Genetische, sowie phänotypische Trends wurden abgeleitet.

Die Daten wurden aus der Datenbank der Polnischen Gesellschaft für Pferdezucht gewonnen. Die Analyse erfasste 494 Warmblut-Hengste, die in den Jahren 2002-2008 am 100-Tage-Test der zwei polnischen Trainingszentren teilgenommen haben.

Die Daten über die Herkunft stammten von 8512 Individuen. Zur Schätzung der Parameter wurde ein beschränktes Wahrscheinlichkeitsminimum angewendet. Die Parameter wurden 
unter dem additiven genetischen Model (eingeschlossen Fixed-Effects: Alter, Zucht, Jahr und Ort der Leistungsprüfung) bestimmt. Die Nonzero-Inzuchtkoeffizienten wurden sowohl für 88 Hengste mit Leistungsnachweis, als auch für ihre 458 Vorfahren ohne Leistungsnachweis geschätzt. Der mittlere Inzuchtgrad bei den Hengsten mit Leistungsnachweis betrug 0,29\%, während für alle ingezüchteten Individuen für diesen Parameter 1,69\% ermittelt wurde. Die mittlere Vollständigkeit des Stammbaums der verzeichneten Hengste betrug 42,47\%. Die geschätzten Werte der Heritabilität variierten zwischen 0,14 (Merkmal) und 0,87 (Gesamtindex). Es wurde festgestellt, dass die Sprungfähigkeit eine relativ hohe Erblichkeit aufwies. Zusammenfassend wurde festgestellt, dass die untersuchten Merkmale geringfügige positive Effekte in genetischen Trends aufwiesen.

Schlüsselwörter: Warmblut Hengste, Leistungsmerkmale, Heritabilität, Inzucht

\section{Introduction}

To find talented horses for sport, a number of traits are recorded. It is well known that »talent« is not an easily measured trait. This character can be considered as a very complex combination of more or less substitutive traits. Koenen et al. (1995) reported positive correlations between conformation traits and sport performance. In Poland the current system of warmblood stallion evaluation includes 30 traits. Three of them, describing body measurements, are typical continuous traits with approximately normal distribution. Unfortunately, other traits are subjectively evaluated by the breeding commission, head of training centre and test riders and expressed on a discrete scale.

One of the major steps in genetic improvement programs is to estimate genetic parameters of the traits, especially heritability and genetic correlations. Various traits associated with talent have been recorded in European countries. Furthermore, they have been evaluated by both field and station tests (see review by Thoren-Hellstein et al. 2006). In general, the estimates of heritability found in stations are higher compared to field tests since residual variance is relatively small (Huizinga et al. 1990).

In Poland the breeding objective for horses has been considerably modified in the last decades, leading to a revision of stallion performance tests (Lewczuk et al. 2004). A current genetic improvement program for warmblood horses has aimed on production of sport horses internationally competive in both dressage and shown jumping. This type of breeding objective is in agreement with several European Warmblood breeding associations (Viklund et al. 2008). Many traits, mostly subjectively scored, are recorded for stallions. To our knowledge, except biometrical traits, no REML estimates of genetic parameters for these traits have been reported in literature. In addition, the inbreeding level has not been monitored for stallions evaluated in the 100-day test over the last years.

The objectives of this study were to estimate the genetic parameters of traits recorded during a 100-day stationary performance test and to predict genetic and phenotypic trends for these traits in Polish warmblood stallions. Furthermore, the inbreeding level in the studied population was estimated. 


\section{Material and methods}

A total population (494 individuals) of Polish warmblood stallions in the stationary performance test conducted between 2002 and 2008 at two Polish Training Centres: Biały Bor and Boguslawice were analyzed.

The number of individuals in each year ranged from 28 to 99 . The stallions participating in the 100-day test were 2 ( 24 individuals), 3 (378 individuals) and 4 (92 individuals) years old. The horses came from national studs as well as from private Polish and foreign breeders. The pedigree included 8512 horses belonging to 18 breeds.

In the study, 25 conformation and performance traits were analyzed. Five traits (free jumping, jumping under rider, walk, trot and canter) were double scored: by head of training centre and by the breeding commission.

Means and standard deviations of the analysed traits are shown in Table 1.

Table 1

Mean and standard deviation for the conformation and performance traits in Polish warmblood stallions

\begin{tabular}{|c|c|c|c|c|c|c|c|}
\hline & Trait & Mean & SD & & Trait & Mean & SD \\
\hline HW & height at withers & 166.56 & 3.10 & TE & temperament & 7.78 & 0.76 \\
\hline $\mathrm{ChC}$ & chest circumference & 191.76 & 4.56 & FJD & free jumping & 7.17 & 0.91 \\
\hline $\mathrm{CaC}$ & cannon circumference & 21.69 & 0.76 & JRD & jumping under rider & 6.85 & 0.95 \\
\hline TY & type & 13.47 & 0.62 & WD & walk & 7.03 & 0.93 \\
\hline $\mathrm{HN}$ & head-neck & 4.01 & 0.36 & TD & trot & 6.98 & 0.91 \\
\hline BO & body & 13.15 & 0.66 & $C D$ & canter & 7.24 & 0.82 \\
\hline $\mathrm{FL}$ & forelegs & 6.68 & 0.56 & FJC & free jumping & 7.06 & 0.85 \\
\hline $\mathrm{HL}$ & hind legs & 6.83 & 0.57 & JRC & jumping under rider & 6.85 & 0.85 \\
\hline $\mathrm{HO}$ & hoofs & 6.99 & 0.51 & WC & walk & 7.14 & 0.66 \\
\hline LW & locomotion walk & 7.18 & 0.65 & $\mathrm{TC}$ & trot & 6.98 & 0.79 \\
\hline LT & locomotion trot & 7.46 & 0.63 & CC & canter & 7.15 & 0.69 \\
\hline Gl & general impression & 13.24 & 0.54 & RA & rideability & 6.06 & 1.77 \\
\hline CS & conformation score & 79.07 & 1.16 & DA & dressage-ability & 5.65 & 1.93 \\
\hline TA & training-ability & 7.16 & 1.00 & $J A$ & jumping-ability & 5.89 & 1.89 \\
\hline $\mathrm{CH}$ & character & 8.55 & 1.08 & $\mathrm{TI}$ & total index & 99.98 & 19.67 \\
\hline
\end{tabular}

SD: standard deviation, HW, ChC, CaC in cm; Score range: 0.0-5.0 for HN; 0.0-15.0 for TY, BO, Gl; 0.0-100 for CS; 0.0-10.0 for other traits, Scores: TY, HN, BO, FL, HL, HO, LW, LT, GI, FJC, JRC, WC, TC, CC, SC, GM by breeding commission; TA, CH, $H F, T E, F J D, J R D, W D, T D, C D$ by head of training centre; RA, DA, JA by test rider

Inbreeding coefficients were estimated using CFC (Contribution, Inbreeding (F), Coancestry) ver 1.0 program (Sargolzaei et al. 2006). Computations of inbreeding coefficients were based on the modified algorithm developed by Colleau (2002), using an additive relationship matrix.

The completeness of pedigree information was assed with the method given by Cassell et al. (2003). The approach is based on a quantitative measure (expressed in percentage) of pedigree completeness in five generations of ancestors.

In preliminary analyses the effects of age, breed group, year, training center and their interactions were tested using PROC GLM of SAS 9.1. (2002-2003). These effects were significant only for rideability, gaits and jumping traits.

The variance components were estimated by the use of the ASREML software (Gilmour et al. 2008). The following single trait linear model was applied:

$$
y=X_{1} \beta_{1}+X_{2} \beta_{2}+X_{3} \beta_{3}+X_{4} \beta_{4}+Z_{1} a+e
$$


where $y$ is the vector of observations of 494 stallions, $\beta_{1}$ is the vector of fixed effects of age ( 3 levels), $\boldsymbol{\beta}_{2}$ is the vector of fixed effects of breed group (6 levels), $\boldsymbol{\beta}_{3}$ is the vector of fixed effects of year (7 levels), $\boldsymbol{\beta}_{4}$ is the vector of fixed effects of training centre (2 levels), $\boldsymbol{a}$ is the vector of random direct additive genetic effects of 8512 individuals, $e$ is the vector of random errors connected with observations, $X_{1}, X_{2}, X_{3^{\prime}} X_{4^{\prime}} Z_{1}$ are the known incidence matrices associated with respective fixed and random effects.

Phenotypic trends were determined by changes of means of the analyzed traits across years. Genetic trends were estimated as changes of average predictors of genetic effects of horses born in consecutive years.

\section{Results and discussion}

Inbreeding level

The whole available pedigree information allowed detection of 546 inbred individuals, including 88 stallions with performance records. For all inbred animals, inbreeding coefficients ranged between $0.01 \%-25 \%$ (Table 2). For the whole population the average inbreeding coefficient was $0.11 \%$. For inbred individuals the average inbreeding level was $1.70 \%$. The number of inbred individuals, the average inbreeding coefficients and the maximum inbreeding coefficients in each year are presented in Table 3. It is well known that accuracy of inbreeding level estimation is considerably determined by pedigree completeness (see e.g. Lutaaya et al. 1999). In the analysed data, the average Cassell coefficient for the recorded stallions was $42.47 \%$.

Table 2

Inbreeding level for all horses in pedigree.

\begin{tabular}{lcc}
\hline Inbreeding coefficient $(\mathrm{F} \%)$ & Number of individuals & Percentage of individuals \\
\hline 0 & 7966 & 93.59 \\
$0<\mathrm{F} \leq 5$ & 505 & 5.93 \\
$5<\mathrm{F} \leq 10$ & 34 & 0.40 \\
$10<\mathrm{F} \leq 15$ & 2 & 0.02 \\
$15<\mathrm{F} \leq 20$ & 1 & 0.01 \\
$20<\mathrm{F} \leq 25$ & 4 & 0.05 \\
\hline
\end{tabular}

Table 3

Inbreeding level for stallions participating in performance tests between 2002 and 2008

\begin{tabular}{lccccc}
\hline Year & $\begin{array}{c}\text { Number of } \\
\text { individuals }\end{array}$ & $\begin{array}{c}\text { Inbred } \\
\text { individuals } \\
\text { coefficient, } \%\end{array}$ & $\begin{array}{c}\text { Average } \\
\text { inbreeding } \\
\text { coefficient, } \%\end{array}$ & $\begin{array}{c}\text { Average } \\
\text { inbreeding in } \\
\text { the inbred, } \%\end{array}$ & $\begin{array}{c}\text { Maximum } \\
\text { inbreeding } \\
\text { coefficient, \% }\end{array}$ \\
\hline 2002 & 13 & 14.61 & 0.10 & 0.70 & 2.15 \\
2003 & 3 & 10.71 & 0.24 & 2.23 & 3.52 \\
2004 & 20 & 21.74 & 0.47 & 2.18 & 7.03 \\
2005 & 17 & 17.17 & 0.24 & 3.38 & 12.50 \\
2006 & 13 & 18.57 & 0.58 & 1.62 & 25.00 \\
2007 & 10 & 14.71 & 0.24 & 0.61 & 7.93 \\
2008 & 12 & 25.00 & 0.15 & 1.69 & 3.13 \\
Total/average & 88 & 17.81 & 0.29 & 25.00 \\
\hline
\end{tabular}


A number of reports on the inbreeding level in Polish horse populations are to be found in the literature (Wolc \& Balińska 2010, Wolc et al. 2009). In general, the level of inbreeding depends on the specific characteristics of a given population, including its size, management, breeding schemes, selection intensity, etc. Also many estimates of inbreeding effects on conformation and performance traits have been published (Curik et al. 2003, Klemetsdal 1998). The results varied across populations. Gomez et al. (2009) reported significant inbreeding depression on body size measurements in Spanish Purebred horses, which affected both performance and the EBV ranking. However, Sierszchulski et al. (2005) found that the inbreeding level in Polish Arabian mares (on average $0.88 \%$ ) did not exert any significant effect on conformation traits. From a methodological perspective, analysis of inbreeding effects on the traits in the studied group of stallions is not possible due to a low number of inbred individuals with phenotypic records.

\section{Genetic parameters}

The heritability estimates are shown in Tables 4 and 5 whereas an abbreviation key for traits recorded are listed in Table 1. The estimates for biometrical measurements (HW, $\mathrm{ChC}, \mathrm{CaC}$ ) ranged from 0.3 to 0.5 . In general, these results are in agreement with ones reported by Gomez et al. (2009) for Spanish Purebred Horses and by Torzynski et al. (2005) for Polish warmblood horses. Similar estimates for exterior traits have also been found for other livestock species (Hagger \& Hofer 1991, Janssens \& Vandepitte 2004).

Table 4

Heritabilities estimates and their approximate standard errors for the analysed conformation and locomotion traits

\begin{tabular}{llc}
\hline & Trait & $\hat{\mathrm{h}}^{2} \pm \mathrm{SE}$ \\
\hline Biometrical measurement & & \\
HW & height at withers, cm & $0.35 \pm 0.20$ \\
ChC & chest circumference, cm & $0.30 \pm 0.20$ \\
CaC & cannon circumference, cm & $0.50 \pm 0.23$ \\
Conformation and locomotion & & \\
TY & type & $0.23 \pm 0.23$ \\
HN & head-neck & $\#$ \\
BO & body & $0.46 \pm 0.28$ \\
FL & forelegs & $\#$ \\
HL & hind legs & $\#$ \\
HO & hoofs & $0.39 \pm 0.23$ \\
LW & locomotion walk & $0.41 \pm 0.28$ \\
LT & locomotion trot & $0.44 \pm 0.26$ \\
GI & general impression & $0.33 \pm 0.25$ \\
CS & conformation score & $0.40 \pm 0.22$ \\
\hline
\end{tabular}

$\hat{h}^{2}$ : heritabilities estimates, SE: standard errors, "due to insufficient variability of traits genetic variance was not detected

For conformation traits the heritability estimates varied from 0.23 (TY) to 0.44 (LT). It should be noted that these results correspond with the ones obtained by other authors for example for type - within 0.23-0.29 (Preisinger et al. 1991, Saastamoinen \& Barrey 2000, Schröder et 
al. 2010). However, in the case of three traits (HN, FL, $\mathrm{HL})$ null genetic variance was estimated. It is strongly affected by a negligible variability of these characters and the consequent non-normality of their distributions. Whereas higher values were estimated for height in withers by Seidlitz et al. (1991) in Arabian mares and by Zechner et al. (2001) in Lipizzan horse population (0.48 and 0.52 ), very similar values (0.31) were found for chest circumference as well as cannon circumference (0.51 and 0.52). Heritabilities estimated by Kapron et al. (1999) on a population of Wielkopolski and Małopolski horses had similar values for height at withers $(0.39$ and 0.34$)$. Smaller estimates than obtained in the present study can be found in the literature for locomotion traits: $0.2-0.3$ for walk as well as 0.21-0.42 for trot (Saastamoinen \& Barrey 2000).

Table 5

Heritability estimates and their standard errors for the analysed performance traits.

\begin{tabular}{llr}
\hline & Trait & $\mathrm{h}^{2} \pm \mathrm{SE}\left(\mathrm{h}^{2}\right)$ \\
\hline Scores by head of training centre & & \\
TA & training-ability & $0.45 \pm 0.20$ \\
CH & character & $0.14 \pm 0.20$ \\
TE & temperament & $0.50 \pm 0.29$ \\
FJD & free jumping & $0.75 \pm 0.21$ \\
JRD & jumping under rider & $0.30 \pm 0.19$ \\
WD & walk & $0.45 \pm 0.24$ \\
TD & trot & $0.75 \pm 0.22$ \\
CD & canter & $0.50 \pm 0.21$ \\
Scores by breeding commission & & \\
FJC & free jumping & $0.79 \pm 0.20$ \\
JRC & jumping under rider & $0.80 \pm 0.22$ \\
WC & walk & $0.43 \pm 0.22$ \\
TC & trot & $0.91 \pm 0.21$ \\
CC & canter & $\#$ \\
Scores by test riders & & \\
RA & rideability & $0.43 \pm 0.27$ \\
DA & dressage-ability & $0.57 \pm 0.22$ \\
JA & jumping-ability & $0.65 \pm 0.20$ \\
TI & total index & $0.87 \pm 0.19$ \\
Accumulated scores & & \\
AFJ & free jumping & $0.87 \pm 0.19$ \\
AJR & jumping under rider & $0.62 \pm 0.21$ \\
AW & walk & $0.50 \pm 0.23$ \\
AT & trot & $0.88 \pm 0.21$ \\
AC & canter & $0.80 \pm 0.20$ \\
Final assessment & & $0.77 \pm 0.20$ \\
\hline
\end{tabular}

$\hat{h}^{2}$ : heritabilities estimates, SE: standard errors, "due to insufficient variability of traits genetic variance was not detected

The heritabilities for the traits scored by the head of the training centre and the breeding commission were quite high, except for $\mathrm{CH}(0.14)$. The highest $h^{2}(0.91)$ was estimated for work in trot. On the other hand it should be stressed that approximated standard deviations of the estimates were relatively large. These results correspond to estimates by Kaproń et 
al. (2001), who estimated heritabilities for performance traits: character (0.10), free jumping (0.85), jumping under rider (0.78). Also similar estimates were obtained for these traits in different countries (Huizinga et al. 1991b, Klemetsdal 1994). Huizinga et al. (1991a) estimated higher heritabilities for work in walk and character $(0.73 ; 0.52)$, while estimates for jumping traits (0.31) were lower.

The observed differences of parameters estimated in this study, in agreement with results reported by other authors can be caused by different numbers of individuals and primarily genetic diversity of populations. As mentioned before, approximated standard deviations of the estimates were relatively large. The heritability estimates may be influenced by genetic structure of crossbred population and therefore overestimated by non-additive genetic effects.

In this study, data were analysed using a linear animal model. By definition, the model is based on a normal distribution of residuals and, in consequences, on polygenic backgrounds of the traits studied. However, this assumption is likely to hold for three biometrical traits, only.

Hence, a threshold animal model has been recommended in the literature to analyze categorical traits (see e.g. Abdel-Azim \& Berger 1999). Threshold methodology has been shown to be theoretically better and is well accepted for estimation of variance components for categorical traits. Thus, both methods of classical point estimation (e.g. REML) and Bayesian ones have been proposed. Unfortunately, computational demands are still overwhelming for threshold models.

In some studies (see e.g. Van Tassell et al. 1998) higher heritability was estimated using a threshold model rather than linear ones, whereas in other reports the results from the threshold and linear models were similar (Kadarmideen et al. 2000, Wolc et al. 2009). It should be noted that linear models are still applied in routine genetic evaluation for exterior traits in horses (Jakubec et al. 2009) and other livestock species (Vukasinovic et al. 1997).

Estimated phenotypic correlations among the performance traits were statistically significant positive (Borowska, unpublished data). Although all available records of evaluated stallions were included in the analysis, the data seem to be too small to estimate genetic correlations between these traits.

\section{Phenotypic and genetic trends}

Average breeding values negligibly fluctuated between years. Generally, the genetic trends were positive (Figure 1-3), in contrast to the phenotypic trends, which showed a decrease of the means for most of traits: assessment of character, training-ability, walk, trot and canter, as well as the characteristics evaluated by test riders. They are not visualised in the Figures.

Genetic trends for four conformation traits are shown in Figure 1. As it can be observed, there are small changes for all characters. Some tendencies are registered for other groups of traits (see Figures 2-3). In these cases, lower averaged values of genetic effects (for free jumping, trot, dressage ability) are observed for stallions born in 2000 and 2003. As it already mentioned a genetic changes for some performance traits are negligible. The changes in both mean annual breeding values and phenotypic averages may be affected by several factors, e.g. contribution of foreign breeds in pedigrees of recorded stallions or their age structure at stationary test period. 


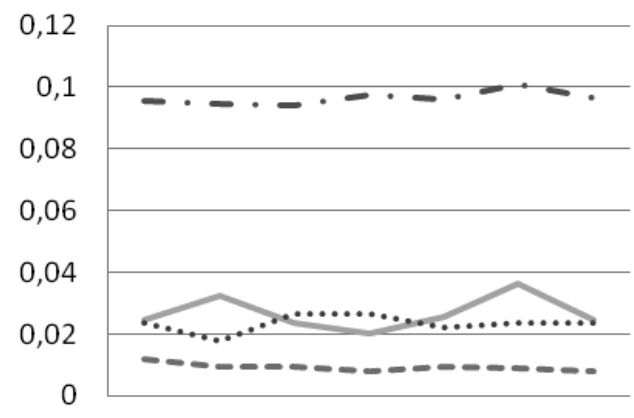

1999200020012002200320042005

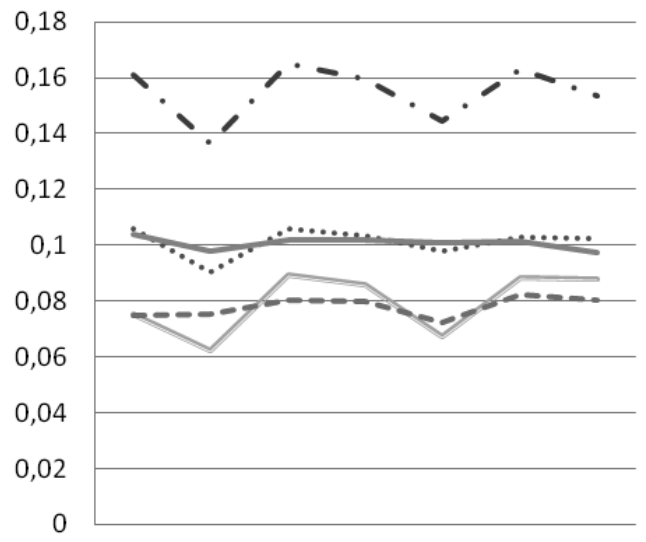

1999200020012002200320042005

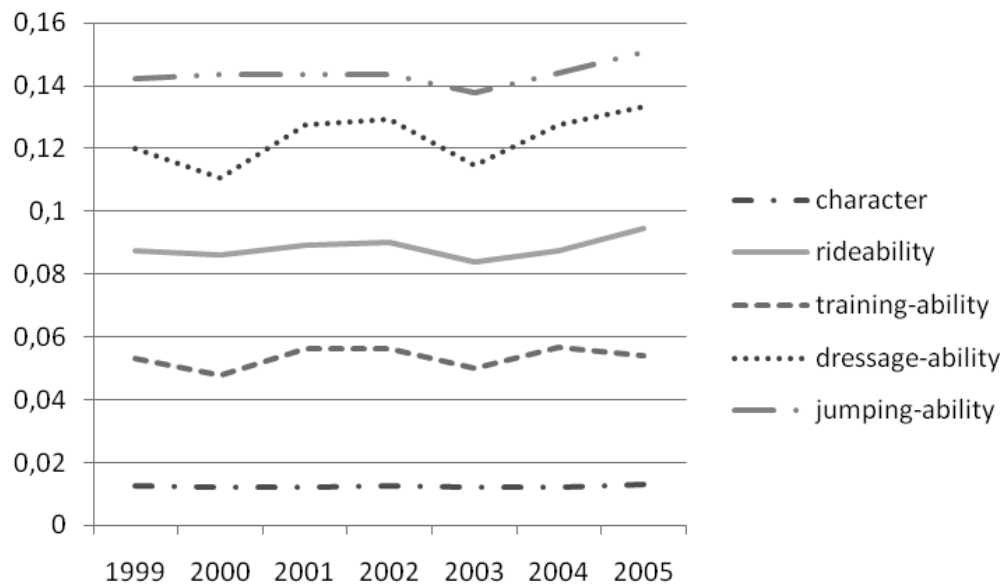

Figure 1

Genetic trends for conformation traits

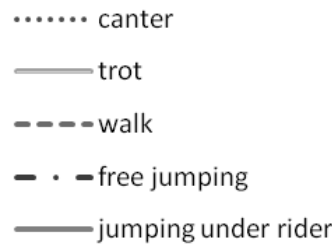

Figure 2

Genetic trends for performance traits

Figure 3

Genetic trends for performance traits 
As already mentioned, routine evaluation of warmblood stallions in Poland is based exclusively on performance tests that follow 100-day training in test stations. The results are expressed in point scales. Statistical analysis of this data type requires a non-standard approach, because the empirical distributions of individual characteristics, by definition deviate from the normal distribution. In the context of the ongoing discussion about the effectiveness of the current evaluation system of horses, a prominent issue is the number of recorded traits, and consequent difficulty to assess the relationships between them. The genetic trends for the traits recorded during performance tests have not changed considerably. It indicates on stability of breeding values of the population studied over time. In the context of insignificant genetic gain for recorded traits as well as global competition of sport horses, some revision of currently realized breeding programs seems to be necessary.

At least four solutions can be considered: modification of procedure for stationary performance test directed to their greater objectivity; reduction of the number of recorded traits, application of new statistical tools to estimate genetic parameters and prediction of breeding values, development of consistent evaluation scheme for males and females, which would allow joined data evaluation.

Lewczuk et al. (2004) presented some attempts to measure performance of horses objectively using such parameters as heart rate, analysis of blood samples taken after the exercise test and free jumping parameters measured by computer photo/image analysis. Moreover, new approaches to analysis of categorical traits have been reported in the literature. One of them is the so-called entropy analysis, which enables reduction of recorded traits according to their contribution in the final assessment. Moore et al. (2006) have described theoretical backgrounds of this methodology among others. Borowska et al. (2010) described the first implementation of this approach to performance evaluation of half-bred stallions.

It is well known that from a theoretical point of view, nonlinear models seem to be more suitable to the analysis of categorical data. Hence, further studies should be focused on the application of threshold or linear-threshold models in routine genetic evaluation in stallions. As expected inbreeding level estimated for the Polish warmblood stallions is relatively low. On the other hand, percentage of inbred stallions was the highest in 2008 year. It may suggest some undesired tendencies in the population.

Phenotypic and genetic trends for performance traits are negligible. Fortunately, a majority of the estimated heritabilities for traits recorded are relatively high. In general, high heritability estimates indicate a possibility of effective selection on majority of traits recorded for Polish warmblood stallions during 100-day performance test.

\section{References}

Abdel-Azim GA, Berger PJ (1999) Properties of threshold model predictions. J Anim Sci 77, 582-590

Borowska A, Dobek A, Molinski K, Szwaczkowski T (2010) A new approach to performance evaluation of half-bred stallions. Workshop »Directions of horse improvement«, Jastrzebiec, Poland http://www.biw. kuleuven.be/genlog/livgen/workshop_Poland2010/SzwaczkowskiJ190310.pdf [last accessed 19.05.2011]

Cassell BG, Adamec V, Pearson RE (2003) Effect of incomplete pedigrees on estimates inbreeding depression for days to first service and summit milk yield in Holsteins and Jerseys. J Dairy Sci 86, 2977-2983

Colleau JJ (2002) An indirect approach to the extensive calculation of relationship coefficients. Genet Sel Evol $34,409-421$ 
Curik I, Zechner P, Sölkner J, Achmann R, Bodo I, Dovc P, Kavar T, Marti T, Brem G (2003) Inbreeding, microsatellite heterozygosity, and morphological traits in Lipizzan Horses. J Heredity 94, 125-132

Gilmour AR, Cullis BR, Welham SJ, Thompson R (2008) ASREML. Reference Manual. NSW Agriculture. Orange. Australia

Gomez MD, Valera M, Molina A, Gutierrez JP, Goyache F (2009) Assessment of inbreeding depression for body measurements in Spanish Purebred (Andalusian) horses. Livest Sci 122, 149-155

Hagger C, Hofer A (1991) Phenotypic and genetic relationships between wither height, heart girth and milk yield in the Swiss Braunvieh and Simmental breeds. Livest Prod Sci 28, 265-271

Huizinga HA, Boukamp M, Smolders G (1990) Estimated parameters of field performance testing of mares from the Dutch Warmblood riding horse population. Livest Prod Sci 26, 291-299

Huizinga HA, van der Werf JHJ, Korver S, van der Meij GJW (1991a) Stationary performance testing of stallions from the Dutch Warmblood riding horse population. 1. Estimated genetic parameters of scored traits and the genetic relation with dressage and jumping competition from offspring of breeding stallions. Livest Prod Sci 27, 231-244

Huizinga HA, Korver S, Van der Meij GJW (1991b) Stationary performance testing of stallions from the Dutch Warmblood riding horse population. 2. Estimated heritabilities of and correlations between successive judgements of performance traits. Livest Prod Sci 27, 245-254

Jakubec V, Vostrý L, Schlote W, Majzlík I, Mach K (2009) Selection in the genetic resource: genetic variation of the linear described type traits in the Old Kladrub horse. Arch Tierz 52, 343-355

Janssens S, Vandepitte W (2004) Genetic parameters for body measurements and linear type traits in Belgian Bleu du Maine, Suffolk and Texel sheep. Small Rum Res 54, 13-24

Kadermideen HN, Thompson R, Simm G (2000) Linear and threshold model genetic parameters for disease, fertility and milk production in dairy cattle. Anim Sci 71, 411-419

Kapron M (1999) Methods of horses improvement. Ed. Agricultural University in Lublin [in Polish]

Kapron M, Zięba G, Czerniak E, Kapron B, Rucinski M (2001) Genetic parameters of performance traits of halfbred stallions trained in Training Stations in 1993-1996. Ann Anim Sci, Supplement 14, $157-167$ [in Polish]

Klemetsdal G (1994) Breeding for performance in horses - a review. Proc 5th WCGALP, University of Guelph, Ontario, Canada, 184-193

Klemetsdal G (1998) The effect of inbreeding on racing performance in Norwegian cold-blooded trotters. Genet Sel Evol 30, 351-366

Koenen EPC, Van Veldhuizen AE, Brascamp EW (1995) Genetic parameters of linear scored conformation traits and their relation to dressage and show-jumping performance in the Dutch Warmblood Riding Horse population. Livest Prod Sci 43, 85-94

Lewczuk D, Szarska E, Pietrzak S (2004) An attempt at objectivization the halfbred stallions' performance test in Poland. Anim Sci Pap Rep 22, 287-296

Lutaaya El, Misztal I, Bertrand JK, Mabry JW (1999) Inbreeding in populations with incomplete pedigrees. J Anim Breed Genet 116, 475-480

Moore JH, Gilbert JC, Tsai CT, Chiang FT, Holden T, Barney N, White BC (2006) A flexible computational framework for detecting, characterizing, and interpreting statistical patterns of epistasis in genetic studies of human disease susceptibility. J Theor Biol 24, 252-261

Preisinger R, Wilkens J, Kalm E (1991) Estimation of genetic parameters and breeding values for conformation traits for foals and mares in Trakehner population and their practical implications. Livest Prod Sci 29, 77-86

Saastamoinen MT, Barrey E (2000) Genetics for Conformation, Locomotion and Physiological Traits. In: Bowling AT, Ruvinsky A (eds.) The Genetics of Horse. Wallingford, UK, 439-472

Sargolzaei M, Iwaisaki H, Colleau J (2006) CFC 1.0. Niigata University, Niigata, Japan

SAS (2002-2003) SAS System for Linux version 9.1. SAS Inst., Cary, NC, USA

Schröder W, Stock KF, Distl O (2010) Genetic evaluation of Hanoverian warmblood horses for conformation traits considering the proportion of genes of foreign breeds. Arch Tierz 53, 377-387 
Seidlitz G, Willeke H, Wemken IVB (1991) Body weight and type traits of purebred Arab breeding mares. Arch Tierz 34, 233-240 [in German]

Sierszchulski J, Helak M, Wolc A, Szwaczkowski T, Schlote W (2005) Inbreeding rate and its effect on three body conformation traits in Arabian mares. Anim Sci Pap Rep 23, 51-59

Thorén Hellsten E, Viklund Å, Koenen EPC, Ricard A, Bruns E, Philipsson J (2006) Review of genetic parameters estimated at stallion and young horse performance tests and their correlations with later results in dressage and show jumping competitions. Livest Sci 103, 1-12

Thorén Hellsten E, Jorjani H, Philipsson J (2009) Genetic correlations between similar traits in the Danish and Swedish Warmblood sport horse populations. Livest Sci 124, 15-20

Torzynski G, Wolc A, Szwaczkowski T (2005) Maternal effects on the conformation traits in half-bred horses. J Anim Feed Sci 14, 595-605

Van Tassell CP, Van Vleck LD, Gregory KE (1998) Bayesian analysis of twinning and ovulation rates using a multiple-trait threshold model and Gibbs sampling. J Anim Sci 76, 2048-2060

Viklund A, Thoren Hellstein E, Näsholm A, Stranberg E, Phillipson J (2008) Genetic parameters for traits evaluated at field tests of 3- and 4-year-old Swedish Warmblood horses. Animal 2, 1832-1841

Vukasinovic N, Moll J, Kunzi N (1997) Factor analysis for evaluating relationships between herd life and type traits in Swiss Brown cattle. Livest Prod Sci 49, 227-234

Wolc A, Balińska K (2010) Inbreeding effects on exterior traits in Polish konik horses. Arch Tierz 53, 1-8

Wolc A, Torzynski G, Szwaczkowski T (2009) Genetic effects on reproductive traits in Warmblood horses. Canadian J Anim Sci 89, 215-218

Zechner P, Zohman F, Sölkner J, Bodo I (2001). Morphological description of the Lipizzan horse population. Livest Prod Sci 69, 163-177

Received 8March 2011, accepted 19 May 2011.

Corresponding author:

Tomasz Szwaczkowski

email: tomasz@jay.au.poznan.pl

Department of Genetics and Animal Breeding, Poznan University of Life Sciences, Wolynska 33, 60-637 Poznan, Poland 